vol.4 No.1 - 2017

\title{
CORRELATION BETWEEN DEPRESSION, ANXIETY AND COPING STRATEGIES AMONG PATIENTS ON MAINTENANCE HEMODIALYSIS: A PILOT STUDY ${ }^{1}$ Ahmed Hashem El-Sayed El-Monshed, ${ }^{2}$ Nelly Ahmed Mahgoub, ${ }^{3}$ Osama Ahmed El-Boraie, ${ }^{4}$ Rania Rabie El-Etreby
}

\author{
1Assistant lecturer of Psychiatric and Mental Health Nursing, Faculty of Nursing-Mansoura University \\ 2 Professor of Psychiatric and Mental Health Nursing, Faculty of Nursing-Cairo University \\ 3Professor of Psychiatry, Faculty of Medicine-Mansoura University \\ 4Lecturer of Psychiatric and Mental Health Nursing, Faculty of Nursing-Mansoura University \\ E-mail: ahmed_elmonshed@mans.edu.eg \\ drahmed014@yahoo.com
}

\begin{abstract}
Background: Chronic kidney disease (CKD) is a growing public health problem worldwide with treatment options of either lifelong hemodialysis or kidney transplant. Hemodialysis patients usually experience intense emotional stress, caused by an inability to cope with various stressors such as sexual dysfunctions, fear of staying alone, restriction of foods, uncertainties about the future, changes in family structure, interferences at work, sleep disorders and psychological disorders such as anxiety and depression. Therefore, the aim of this pilot study is to assess the correlation between depression and anxiety with coping strategies among patients on maintenance hemodialysis. Method: A descriptive correlation research design was conducted in the hemodialysis units at the New Mansoura General Hospital. The data were collected from 41 hemodialysis patients who corresponded to the inclusion and exclusion criteria. Beck Depression Inventory (BDI-II), Beck Anxiety Inventory (BAI), and Dealing with Illness Inventory were used to achieve the purpose of the pilot study. Results: The results of the current pilot study revealed that depression and anxiety had statistically significant negative correlations with both active cognitive and active behavior coping $(\mathrm{P}<0.05)$ while they had statistically significant positive correlations with avoidance coping $(\mathrm{P}<0.05)$. Conclusion: Increasing the use of active cognitive and active behavior coping strategies is effective way to reduce symptoms of depression and anxiety. Application of psychiatric nursing intervention programs in hemodialysis units is recommended to enhance using of active coping strategies and discourage using of dysfunctional coping strategies to decrease depressive and anxiety symptoms.
\end{abstract}

Keywords: Chronic Kidney Disease; Hemodialysis; Depression; Anxiety; Coping.

Abbreviations: CKD (Chronic Kidney Disease)

\section{Introduction:}

Chronic kidney disease (CKD) is a significant and worldwide public health problem in current times; it is an irreversible loss of kidney function. Accordingly, defined CKD as abnormal kidney function or structure persisting greater than 3 months ${ }^{[1]}$. Currently in Egypt, hemodialysis considers the main treatment modality of CKD patients ${ }^{[2]}$. In Egypt, the prevalence of hemodialysis patients has increased from 10 per million population (pmp) in 1974 to $225 \mathrm{pmp}$ in 
1996, and then from $403 \mathrm{pmp}$ in 2003 to 483 in $2004^{[3]}$.

Hemodialysis is a sustained symptomatic treatment that adversely affects patients both physically and mentally resulting in psychological problems include depression, anxiety, poor life quality, fatigue, and high suicide risk. The global effects of maintenance hemodialysis lead to changes in patient's social and occupational functions, with feelings of control loss, helplessness, decrease the patient's self-esteem, loneliness, inhibiting coping, and fear of death $^{[4]}$. Furthermore, it is also not surprising, hemodialysis patients report high rates of psychological distress. The prevalence of psychiatric hospitalization among them is 1.5-3 times higher compared to other chronic diseases ${ }^{[5]}$.

Depression and anxiety are generally accepted to be the commonest psychological problems encountered in CKD patients on hemodialysis treatment ${ }^{[6]}$. The prevalence of total depression among hemodialysis patients was reported as $80 \%$ classified into mild, moderate and severe depression with prevalence of $25 \%, 50 \%$, and $25 \%$ respectively ${ }^{[7]}$. On the other hand, the prevalence of anxiety were reported as $47.5 \%$ of 80 hemodialysis patients had mild anxiety levels, while $48.7 \%$ had moderate or severe levels of anxiety $^{[8]}$.

Hence, hemodialysis treatment requires patients to make a number of adjustments to adapt with a ceaseless physical disorder and the need much of the time of coping with dependence on a dialysis machine to stay alive $\mathrm{e}^{[9]}$. In psychology, coping strategy is understood as reasonable, adaptive behavior, rational, oriented on removal or psychological overcoming of critical situation. It is considered that coping depends on human personality, conditions of social support, and actual situation. It manifests in cognitive, in emotional and in behavioral spheres of personality ${ }^{[10]}$.

Coping with chronic illnesses such as CKD is always a threatening and a challenging process, and healthcare providers especially nurses need to be aware of these conditions. If coping strategies are used effectively, they can help in improving well-being and overcoming depression and anxiety of patients $^{[11]}$. Therefore it is deemed necessary to conduct this pilot study.

Aim of the pilot study:

The pilot study was conducted to assess the correlation between coping strategies, depression, and anxiety among patients on maintenance hemodialysis.

\section{Patients and Method}

Design:

The pilot study was carried out using a descriptive cross-sectional research design.

Setting:

The pilot study was conducted at the Dialysis Units of the New Mansoura General Hospital.

Sample:

A purposive sample of 41 hemodialysis patients after screening of all patients attending hemodialysis units at the beginning time of the pilot study for the following "inclusion and exclusion criteria":

\section{Inclusion criteria:}

1. Patients who had symptoms of both depression and anxiety (mild, moderate or severe) according to Beck's Depression Inventory ${ }^{[12]}$ and Beck's Anxiety Inventory ${ }^{[13]}$.

2. Patients who were on maintenance hemodialysis for a period of (3-36) months.

3. Age: from twenty to forty years old.

4. At least 12 years of education.

\section{Exclusion criteria:}

1. Patients with Acute Kidney Disease.

2. Patients with scores of < fourteen i.e., below the threshold validated for 
CORRELATION BETWEEN DEPRESSION, ANXIETY AND etc...

depression on Beck Depression Inventory and those with scores < eight i.e., below the threshold validated for anxiety on Beck Anxiety Inventory.

Tools for data collection:

\section{Socio-demographic and Clinical} Data Structured Interview Schedule: was developed by the investigator to assess demographic and clinical data related to sample such as: sex, age, marital status, residence, occupation, years of education, duration of hemodialysis and hemodialysis comorbidity.

2. Beck Depression Inventory $(\text { BDI-II })^{[12]}$ : Developed in response to the American Psychiatric Association's publication of the "Diagnostic and Statistical Manual of Mental Disorders, Fourth Edition (DSMIV)". The BDI-II was translated into Arabic language and validated by Ghareeb $^{[14]}$. This inventory includes 21 items measuring the severity of depressive symptoms. The final score interpretation is given as follows: absence of depression between (0-13); mild depression between (14-19); moderate between (20-28); and severe depression between (2963).

3. Beck Anxiety Inventory (BAI) $^{[13]}$ : was developed to assess the symptoms of anxiety in adults. The BAI has 21 items that assess anxiety intensity. A score of 0-7 refers to minimum level of anxiety; 8-15 mild anxiety, 16-25 moderate and 26-63 severe anxiety. The BAI was translated into Arabic language and validated by Al-Nehar and Al-Zubaidi ${ }^{[15]}$.

4. Dealing with Illness Inventory: was originally developed by
Namir, Wolcot, Fawzy, et. al. ${ }^{[10]}$.

This inventory assesses cognitive and behavioral responses made in effort to cope with the illness. It is a self-administered inventory with forty-eight statements assessing three main coping methods are: active cognitive coping, active behavior coping, and avoidance coping. This inventory was translated into Arabic language and validated by Foad ${ }^{[17]}$.

The range of active-cognitive efforts is 16-80, with higher scores meaning higher use of active-cognitive strategies. These efforts include altering one's beliefs, attitudes, and thoughts about the disease. Active-behavioral efforts include reliance on others for emotional, informational, and instrumental support as well as selfhelp efforts. The range of activebehavioral efforts is 20-100, with higher scores meaning higher use of activebehavioral strategies. Avoidant dealing with illness efforts include selfmedication with alcohol and drugs exemplify avoidant coping with illnesses. The range of avoidant dealing with illness efforts is 12-60, with higher scores meaning higher use of avoidant dealing with illness strategies. Active cognitive and active behavioral dealing with illness/coping methods are considered to be positive strategies; whereas the avoidant dealing with illness/coping method is considered to be a negative strategy.

Method:

Official permissions were attained from the head of the hemodialysis department to conduct the pilot study. Informal consent was attained from the respondents before their inclusion in the pilot study. The aim of the pilot study was explained to each member of the participants. Each patient was individually interviewed to collect the necessary data in privacy. Ethical considerations were 
obtained from the Research Ethics Committee of the Faculty of Nursing Mansoura University.

\section{Statistical analysis:}

Data were analyzed by SPSS version 21. The normality of data was firstly tested by one-sample KolmogorovSmirnov test. Qualitative data were presented using numbers and percentage. Continuous variables were presented as mean \pm SD (standard deviation) for parametric data. Pearson correlation used for the correlation between continuous parametric data.

\section{Results:}

In relation to the sociodemographic data of the studied patients, the pilot study results demonstrated that more than half of the studied patients $(53.7 \%)$ were males while $46.3 \%$ were females. As regard to the age, the majority of the studied patients $(80.5 \%)$ were 30 -

40 years. Concerning the residence, around two thirds of the studied patients $(65.9 \%)$ were lived in rural areas. In relation to the marital status, the majority of the studied patients $(85.4 \%)$ were married. Regarding the years of education, around than two thirds of the studied patients (65.9\%) were educated for 12 years while $34.1 \%$ were educated for $>12$ years. Concerning the occupation, more than half of the studied patients $(56.1 \%)$ were working patients (Table, 1).

Regarding the clinical data, the pilot study finding showed that more than two fifth of the studied patients (43.9\%) undergone hemodialysis for duration from 3 months to less than one year, while $31.7 \%$ of the studied patients undergone hemodialysis for duration $24-36$ months. In relation to the hemodialysis comorbidity, more than half of the studied patients $(63.4 \%)$ had hemodialysis comorbidity such as diabetes mellitus, thyroid diseases hypertension, cardiac diseases and hepatitis B or C (Table, 2).

As regard to the score of depression, the pilot study results revealed that the mean score of depression was

21.75 out of a possible score 63. As regard to the score of anxiety, the pilot study findings demonstrated that the mean score of anxiety was 20.24 out of a possible score 63. Concerning the coping strategies used by the studied patients, the results of the pilot study indicated that means of scores of active cognitive coping, active behavior coping, and avoidance coping were $45.87,47.02$, and 23.07 out of a possible score of 80, 100, and 60 respectively (Table, 3 ).

The pilot study results revealed that depression and anxiety had statistically significant negative correlations with active cognitive coping and active behavior coping $(\mathrm{P}<0.05)$ and had statistically significant positive correlations with avoidance coping $(\mathrm{P}<0.05$; Table, 4$)$. 
CORRELATION BETWEEN DEPRESSION, ANXIETY AND etc...

\begin{tabular}{|c|c|c|c|}
\hline \multicolumn{2}{|c|}{ Socio-demographic characteristics } & Number & $\%$ \\
\hline \multirow[t]{2}{*}{ Sex } & Male & 22 & 53.7 \\
\hline & Female & 19 & 46.3 \\
\hline \multirow{2}{*}{ Age in years } & $20-(<30)$ & 8 & 19.5 \\
\hline & $30-40$ & 33 & 80.5 \\
\hline \multirow[t]{2}{*}{ Residence } & Rural & 27 & 65.9 \\
\hline & Urban & 14 & 34.1 \\
\hline \multirow{3}{*}{ Marital status } & Single & 4 & 9.8 \\
\hline & Married & 35 & 85.4 \\
\hline & Divorced & 2 & 4.9 \\
\hline \multirow{2}{*}{ Years of education } & $=12$ Years & 27 & 65.9 \\
\hline & $>12$ Years & 14 & 34.1 \\
\hline \multirow[t]{2}{*}{ Occupation } & Jobless & 18 & 43.9 \\
\hline & Working & 23 & 56.1 \\
\hline
\end{tabular}

Table (2): Clinical data of the studied patients $(n=41)$ :

\begin{tabular}{|c|c|c|c|}
\hline \multicolumn{2}{|c|}{ Clinical Data } & Number & $\%$ \\
\hline \multirow{3}{*}{$\begin{array}{c}\text { Hemodialysis duration in } \\
\text { years }\end{array}$} & $3-(<12)$ months & 18 & 43.9 \\
\hline & $12-(<24)$ months & 10 & 24.4 \\
\hline & $(24-36)$ months & 13 & 31.7 \\
\hline \multirow{2}{*}{$\begin{array}{l}\text { Hemodialysis co- } \\
\text { morbidity }\end{array}$} & No Co-morbidity & 15 & 36.3 \\
\hline & Co-morbidity & 26 & 63.4 \\
\hline
\end{tabular}

Table (3): Mean and SD of depression, anxiety, and coping strategies:

\begin{tabular}{|c|c|}
\hline \hline The studied variables & Mean \pm SD \\
\hline Depression & $21.75 \pm 5.53$ \\
\hline Anxiety & $20.24 \pm 7.56$ \\
\hline & \\
\hline & \\
\hline Active Cognitive Coping & $45.87 \pm 6.33$ \\
\hline Active Behavior Coping & $47.02 \pm 7.14$ \\
\hline \multicolumn{2}{|c|}{} \\
\hline Avoidance Coping & $23.07 \pm 4.42$ \\
\hline
\end{tabular}


Ahmed Hashem El-Sayed El-Monshed et. al.

\begin{tabular}{|c|c|c|c|c|}
\hline \multirow{2}{*}{ Studied Variables } & \multicolumn{2}{|c|}{ Depression } & \multicolumn{2}{|c|}{ Anxiety } \\
\hline & $\mathbf{r}$ & $\mathbf{P}$ & $\mathbf{r}$ & $\mathbf{P}$ \\
\hline $\begin{array}{l}\text { Active Cognitive } \\
\text { Coping }\end{array}$ & -0.443 & $0.004 *$ & -0.653 & $\leq 0.001 *$ \\
\hline $\begin{array}{c}\text { Active Behavior } \\
\text { Coping }\end{array}$ & -0.400 & $0.010^{*}$ & -0.522 & $\leq 0.001^{*}$ \\
\hline Avoidance Coping & 0.374 & $0.016^{*}$ & 0.445 & $0.004 *$ \\
\hline
\end{tabular}

(*) Statistically significant at $\mathrm{p}<0.05$

\section{Discussion:}

Hemodialysis patients need to cope with various aspects of their illness. Recognizing the coping skills and their associations with symptoms of depression and anxiety provides valuable information for planning specific management and medical care delivery and improving the performance of dialysis nurses. The findings of the current pilot study revealed that depression and anxiety had significant negative correlations with active cognitive coping and active behavior coping. These results indicated that symptoms of depression and anxiety increase with decreasing the use of active cognitive coping methods and active behavior strategies and vice versa.

These results might be explained that active cognitive coping methods such as "acceptance, facing and solving the problem thinking about the positive changes and meaning of life, planning, praying and trusting in God, identifying the nature of illness and determining its needs, and gaining experiences from other patients with the same illness" are very useful strategies for improving patients' attitudes, beliefs, and thoughts about hemodialysis treatment, decreasing their involuntary responses, and help them to become more accustomed to hemodialysis treatment and might perceive it as a routine activity that result in decreasing their symptoms of depression and anxiety.

Regarding the active behavior coping methods such as "becoming more socially, seeking help to change things in the situation, reliance on others for emotional, informational, and instrumental support, self-help efforts, turned to work or other things to keep ray mind off, enjoyed every day events, exercised more, used meditation, self-hypnosis or imagery, and cried, yelled, or laughed more to express feelings" are helpful skills for the patients in managing stresses, finding emotional and social support, improving mood state, and expressing their feeling in desirable ways that result in decreasing their symptoms of depression and anxiety.

In relation to the avoidance coping methods, the current pilot study results showed that depression and anxiety had significant positive correlations with avoidance coping. These results indicated that symptoms of depression and anxiety increase with increasing the use of avoidance coping methods and vice versa. These findings could be explained that avoidance coping methods such as "hide feelings, being alone, refusing to think about the problem, escaping from facing 
CORRELATION BETWEEN DEPRESSION, ANXIETY AND etc...

the problem through eating or sleeping more than usual and smoking or taking drugs, making fun, and daydreaming" make the patients were uncertain how to manage their problems or felt inadequate to deal with them in a problem solving way and suppress their feeling toward hemodialysis treatment that result in increasing their symptoms of depression and anxiety.

These pilot study findings are congruent with a recent study reported that that low mood is related to an increase in maladaptive attitude toward chronic kidney disease ${ }^{[18]}$. Similarly, another study reported that depression scores had a negative correlation with active problem focused coping strategies and active emotional focused coping strategies and had a positive correlation with dysfunctional coping strategies ${ }^{[19]}$. In addition, another study found negative relationship between spiritual coping and levels of depression ${ }^{[20]}$. Moreover, similar study reported that depression and anxiety had significant negative correlation with task oriented coping skills ${ }^{[21]}$.

Conversely, Welch and Austin ${ }^{[22]}$ reported that there was no relationship between problem solving coping strategies and depression. Additionally, Shinde and Mane $^{[23]}$ found non-significant negative correlation between stressors and coping scores.

Regarding avoidance coping, the current pilot study results is consistent with the study conducted by Welch and Austin $^{[22]}$ who mentioned that more avoidance coping predicted more depression symptoms. In other study, avoidance coping strategies was negatively associated with depression but was not associated with anxiety ${ }^{[24]}$.

\section{Conclusion:}

To conclude, a negative correlation exists between depression and anxiety and both active cognitive and active behavior coping strategies wile a positive correlation exists between depression and anxiety and avoidance coping strategies. Thus, increasing the use of active cognitive and active behavior coping strategies is effective way to reduce symptoms of depression and anxiety.

\section{Recommendation:}

The pilot study recommends that, assessment of psychological state and coping strategies of hemodialysis patients should be conducted by all health care providers. Application of psychiatric nursing intervention programs in hemodialysis units is recommended to enhance using of active coping strategies and discourage using of dysfunctional coping strategies to decrease symptoms of depression and anxiety.

\section{Acknowledgements:}

We would like to thank all the patients who participated in the study and dialysis staff of the New Mansoura General Hospital for their help and cooperation during the pilot study period and appreciate the great efforts of the supervisors in this work.

\section{References:}

1. Egbi OG, Ogunrin O, Oviasu E. Prevalence and determinants of cognitive impairment in patients with chronic kidney disease: a crosssectional study in Benin City, Nigeria. Ann Afr Med. 2015;14(2):75-81. 
2. Ahmed A, Allam M, Habil E, Metwally A, Ibrahiem N, Radwan $\mathrm{M}$, et al. Development of practice guidelines for hemodialysis in Egypt. Indian J Nephrol. 2010;20(4):193-202.

3. Kamal NN, Kamel EG, Eldessouki $\mathrm{KH}$, Ahmed MG. Health-related quality of life among hemodialysis patients at El-Minia University Hospital, Egypt. J Public Health.

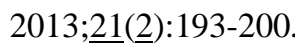

4. Wang L, Chen C. The Psychological Impact of Hemodialysis on Patients with Chronic Renal Failure. 2009; 217-236. Available from: http:// www.intechopen.com

5. Baykan H, Yargic I. Depression, anxiety disorders, quality of life and stress coping strategies in hemodialysis and continuous ambulatory peritoneal dialysis patients. Bulletin of Clinical Psychopharmacology.

2012;22(2):167-76.

6. Chan R, Steel Z, Brooks R, Heung T, Erlich J, Chow J, et al. Psychosocial risk and protective factors for depression in the dialysis population: A systematic review and meta-regression analysis. J Psychosom Res. 2011;71(5):300-10.

7. Hamody ART, Kareem AK, AlYasri ARS, Sh Ali AA-H. Depression in Iraqi hemodialysis patients. Arab J Nephrol Transplant. 2013;6(3):169-72.

8. Bossola M, Ciciarelli C, Conte GL, Vulpio C, Luciani G, Tazza L. Correlates of symptoms of depression and anxiety in chronic hemodialysis patients. Gen Hosp

Psychiatry. 2010;32(2):125-31.

9. Ramasubramanian V, Ponnudurai R, Soundararajan P, Balakrishnan K, Srinivasan B. Depression, anxiety disorders, quality of life and stress coping strategies in hemodialysis and continuous ambulatory peritoneal dialysis patients. Asian J Pharm Clin Res. 2012;22(2):167-76.

10. Pichurin V V. Coping strategies and psychological readiness of students for professional work. 2015;53-9.

11. Parvan K, Ahangar R, Hosseini FA, Abdollahzadeh F, Ghojazadeh M, Jasemi M, Coping methods to stress among patients on hemodialysis and peritoneal dialysis. Saudi J Kidney Dis Transpl. 2015;26(2):255-262.

12. Beck AT, Steer RA, Brown GK (1996). Manual for the Beck Depression Inventory-II. San Antonio, TX: Psychological Corporation. 1996.

13. Beck AT, Epstein N, Brown G, Steer RA, others. An inventory for measuring clinical anxiety: Psychometric properties. J Consult Clin Psychol. 1988;56(6):893-7.

14. Ghareeb A G. Manual of Arabic BDI-II. Alongo Press. Cairo Inventory: The author's twenty -five years of evaluation. Clinical Psychology Review. 2000; 8: 77100.

15. Al-Nehar T, Al-Zubaidi A. The Psychometric Properties of the Arabic Version of Beck Anxiety Inventory in United Arab Emirates. Journal of the Educational Research Center. 2000;18: 87-106. 
CORRELATION BETWEEN DEPRESSION, ANXIETY AND etc...

16. Namir S, Wolcot D, Fawzy F, Alumbaugh M J. Coping with AIDS.

Psychological and Health Implications. J. Appl. Psychol. 1987; 17: 309-328.

17. Foad A. Coping strategies in Egyptian cancer patients. MS thesis. Supervised by Dr Abdel Azzim S, El-Raee L and Bakry A. Cairo University.1999.

18. Kokoszka A, Leszczyńska K, Radzio R, Daniewska D, Łukasiewicz A, Orzechowski W, et al. Prevalence of depressive and anxiety disorders in dialysis patients with chronic kidney disease. Arch Psychiatry Psychother. 2016;18(1):8-13.

19. Keskin G, Engin E. The evaluation of depression, suicidal ideation and coping strategies in haemodialysis patients with renal failure. J Clin Nurs. 2011;20(19-20):2721-32.
20. Koenig HG. Spirituality and depression: A look at the evidence. South Med J. 2007;100:737-79.

21. Takaki J, Nishi T, Shimoyama H, Inada T, Matsuyama N, Kumano $\mathrm{H}$, et al. Interactions among a stressor, self-efficacy, coping with stress, depression, and anxiety in maintenance hemodialysis patients. Behav Med. 2003;29(3):107-12.

22. Welch JL, Austin JK. Stressors, coping and depression in haemodialysis patients. J Adv Nurs. 2001;33(2):200-7.

23. Shinde M, Mane SP. Stressors and the Coping Strategies among Patients Undergoing Hemodialysis. 2014;3(2):266-76.

24. Takaki J, Nishi T, Shimoyama H, Inada T, Matsuyama N, Kumano $\mathrm{H}$, et al. Possible interactive effects of demographic factors and stress coping mechanisms on depression and anxiety in maintenance hemodialysis patients. J Psychosom Res. 2005;58(3):217-23 